\title{
The plant coumarins auraptene and lacinartin as potential multifunctional therapeutic agents for treating periodontal disease
}

\author{
Annie Marquis ${ }^{1}$, Salvatore Genovese ${ }^{2}$, Francesco Epifano ${ }^{2}$ and Daniel Grenier ${ }^{* *}$
}

\begin{abstract}
Background: Periodontal diseases are bacterial infections leading to chronic inflammation disorders that are frequently observed in adults. In the present study, we evaluated the effect of auraptene and lacinartin, two natural oxyprenylated coumarins, on the growth, adherence properties, and collagenase activity of Porphyromonas gingivalis. We also investigated the capacity of these compounds to reduce cytokine and matrix metalloproteinase (MMP) secretion by lipopolysaccharide (LPS)-stimulated macrophages and to inhibit MMP-9 activity.

Methods: Microplate dilution assays were performed to determine the effect of auraptene and lacinartin on $P$. gingivalis growth as well as biofilm formation stained with crystal violet. Adhesion of FITC-labeled $P$. gingivalis to oral epithelial cells was monitored by fluorometry. The effects of auraptene and lacinartin on LPS-induced cytokine and MMP secretion by macrophages were determined by immunological assays. Fluorogenic assays were used to evaluate the capacity of the two coumarins to inhibit the activity of $P$. gingivalis collagenase and MMP-9.
\end{abstract}

Results: Only lacinartin completely inhibited $P$. gingivalis growth in a complex culture medium. However, under iron-limiting conditions, auraptene and lacinartin both inhibited the growth of $P$. gingivalis. Lacinartin also inhibited biofilm formation by $P$. gingivalis and promoted biofilm desorption. Both compounds prevented the adherence of $P$. gingivalis to oral epithelial cells, dose-dependently reduced the secretion of cytokines (IL-8 and TNF- $a$ ) and MMP-8 and MMP-9 by LPS-stimulated macrophages, and inhibited MMP-9 activity. Lacinartin also inhibited $P$. gingivalis collagenase activity.

Conclusions: By acting on multiple targets, including pathogenic bacteria, tissue-destructive enzymes, and the host inflammatory response, auraptene and lacinartin may be promising natural compounds for preventing and treating periodontal diseases.

Keywords: Coumarins, Auraptene, Lacinartin, Antibacterial, Anti-adherence, Anti-inflammatory

\section{Introduction}

Periodontal diseases are chronic inflammatory disorders of bacterial origin that affect tooth-supporting tissues [1]. It is estimated that $5 \%$ to $20 \%$ of any population suffers from severe, generalized periodontitis, while mild to moderate periodontitis affects a majority of adults [2]. These diseases are mixed infections induced by a specific group of Gramnegative anaerobic bacteria called periodontopathogens [3]. Of the over 700 bacterial species that have been identified

\footnotetext{
* Correspondence: daniel.grenier@greb.ulaval.ca

'Groupe de Recherche en Écologie Buccale, Faculté de Médecine Dentaire, Université Laval, 2420 Rue de la Terrasse, Quebec City, QC, Canada G1V OA6 Full list of author information is available at the end of the article
}

in the oral cavity [4] only a few are associated with periodontitis, including Porphyromonas gingivalis [5]. This bacterial species produces a number of virulence factors that contribute to host colonization, immune defense system neutralization, and periodontal tissue destruction [5]. High numbers of $P$. gingivalis, together with other periodontopathogens, induce a host immune response, which in turn leads to a destructive inflammatory process [6,7].

Over the past two decades, there has been increasing interest in the potential human health benefits of natural compounds [8]. Polyphenols, which are well known for their antioxidant properties, contribute to the protection of deoxyribonucleic acid (DNA) and macromolecules

\section{Biomed Central}


(lipids and proteins) and can prevent some types of cancers, cardiovascular diseases, and other disorders associated with oxidative stress [9,10]. These natural compounds are members of a large class of organic molecules that are widely distributed in the plant kingdom and, as such, are an integral part of the daily diet of humans [11,12]. Since polyphenols have been reported to possess antimicrobial and anti-inflammatory properties, they may be of interest as therapeutic agents for controlling periodontal diseases, which involve both pathogenic bacteria and host immune responses.

Auraptene and lacinartin are polyphenols that belong to the coumarin family $[13,14]$. While the chemical structures of these two compounds are similar, lacinartin has a methoxy group on the benzene ring and an isopentenyloxy side chain (Figure 1). Auraptene, which is also known as 7-geranyloxycoumarin, was first isolated in the 1930s by Komatsu et al. [15]. It is the most abundant naturally occurring prenyloxycoumarin and is mostly found in Citrus fruits $[13,16,17]$. Auraptene has been reported to possess antioxidant, anti-inflammatory, antibacterial, and anticancer properties [18,19] while little is known about lacinartin.

To the best of our knowledge, no one has investigated the potential beneficial effects of auraptene and lacinartin on oral health. We hypothesized that auraptene and lacinartin may be promising natural compounds that could be used to prevent and treat periodontal diseases. We thus evaluated the effects of these compounds on the growth, biofilm formation/ desorption, and adherence to human oral epithelial cells of $P$. gingivalis. We also investigated their antiinflammatory properties using a macrophage model as well as their ability to inhibit MMP-9 and P. gingivalis collagenase.

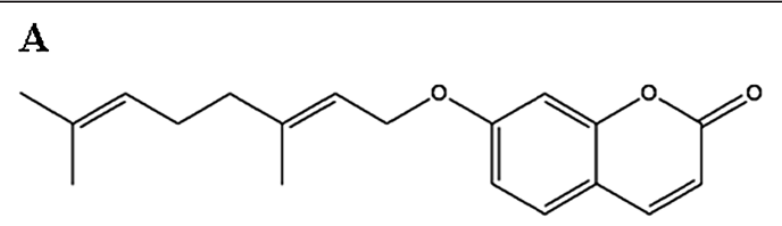

B

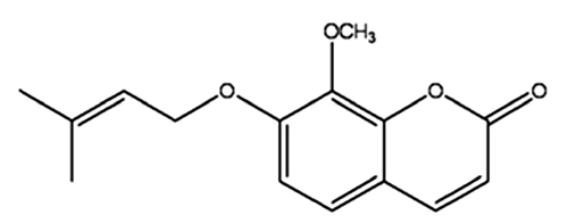

Figure 1 Chemical structures of auraptene (A) and lacinartin (B).

\section{Materials and methods Compounds}

Auraptene was purchased from Sigma-Aldrich Corp. (St. Louis, MO, USA). Lacinartin, an oxyisopentenylated coumarin, was produced using a previously reported procedure [20]. Briefly, commercially available propiolic acid and pyrogallol were condensed by concentrated $\mathrm{H}_{2} \mathrm{SO}_{4}$ catalysis into daphnetin via a Pechmann reaction. The daphnetin was then selectively alkylated on position 7 of the coumarin ring with 3,3-dimethylallyl bromide and 1,8-diazabicyclo [5.4.0] undec-7-ene (DBU). It was then methylated on position 8 with methyl iodide and triethylamine to yield lacinartin. The final yield was $62 \%$. Stock solutions of auraptene and lacinartin were prepared in dimethyl sulfoxide $(10 \mathrm{mg} / \mathrm{ml})$ and stored at $4^{\circ} \mathrm{C}$ in the dark.

\section{Effect on Porphyromonas gingivalis growth}

P. gingivalis ATCC 33277 was purchased from the American Type Culture Collection (Manassas, VA, USA). Bacteria were routinely grown in Todd-Hewitt broth (BBL Microbiology Systems, Mississauga, ON, Canada) supplemented with $20 \mu \mathrm{M}$ hemin and $0.0001 \%$ vitamin $\mathrm{K}$ (THB-HK) at $37^{\circ} \mathrm{C}$ under anaerobic conditions $\left(80 \% \mathrm{~N}_{2} / 10 \% \mathrm{H}_{2} / 10 \% \mathrm{CO}_{2}\right)$ for $24 \mathrm{~h}$. The effect of auraptene and lacinartin on $P$. gingivalis growth was assessed in two different culture media using a microplate dilution assay. THB-HK contained excess iron, while Mycoplasma broth base (MBB; BBL Microbiology Systems) supplemented with $10 \mu \mathrm{M}$ hemin (MMB-H) contained limited iron. Briefly, 24-h cultures of $P$. gingivalis in THB-HK, or MBB-H were diluted in fresh broth medium to obtain an optical density of 0.2 at $660 \mathrm{~nm}$ $\left(\mathrm{OD}_{660}\right)$. Equal volumes $(100 \mu \mathrm{l})$ of $P$. gingivalis suspension and auraptene or lacinartin $(0,12.5,25,50,100 \mu \mathrm{g} /$ $\mathrm{ml}$ ) in THB-HK, or MBB-H were mixed in the wells of 96-well plates (Sarstedt, Newton, NC, USA). Wells with no $P$. gingivalis, auraptene, or lacinartin were used as controls. After a 48 -h incubation at $37^{\circ} \mathrm{C}$ under anaerobic conditions, bacterial growth was determined by measuring the $\mathrm{OD}_{660}$ using a microplate reader.

\section{Effect on $P$. gingivalis biofilm formation/desorption}

$P$. gingivalis was grown in THB-HK supplemented or not with auraptene or lacinartin as described above. After a 48-h incubation under anaerobic conditions, spent medium and free-floating bacteria were removed by aspiration using a $26 \mathrm{G}$ needle, and the wells were washed three times with $50 \mathrm{mM}$ phosphate-buffered saline (PBS) pH 7.0. The biofilms were stained with $100 \mu \mathrm{l}$ of $0.02 \%$ crystal violet for $15 \mathrm{~min}$. The wells were then washed three times with PBS to remove unbound dye and were dried for $2 \mathrm{~h}$ at $37^{\circ} \mathrm{C}$. Ethanol (100 $\mu \mathrm{l}, 95 \%$ 

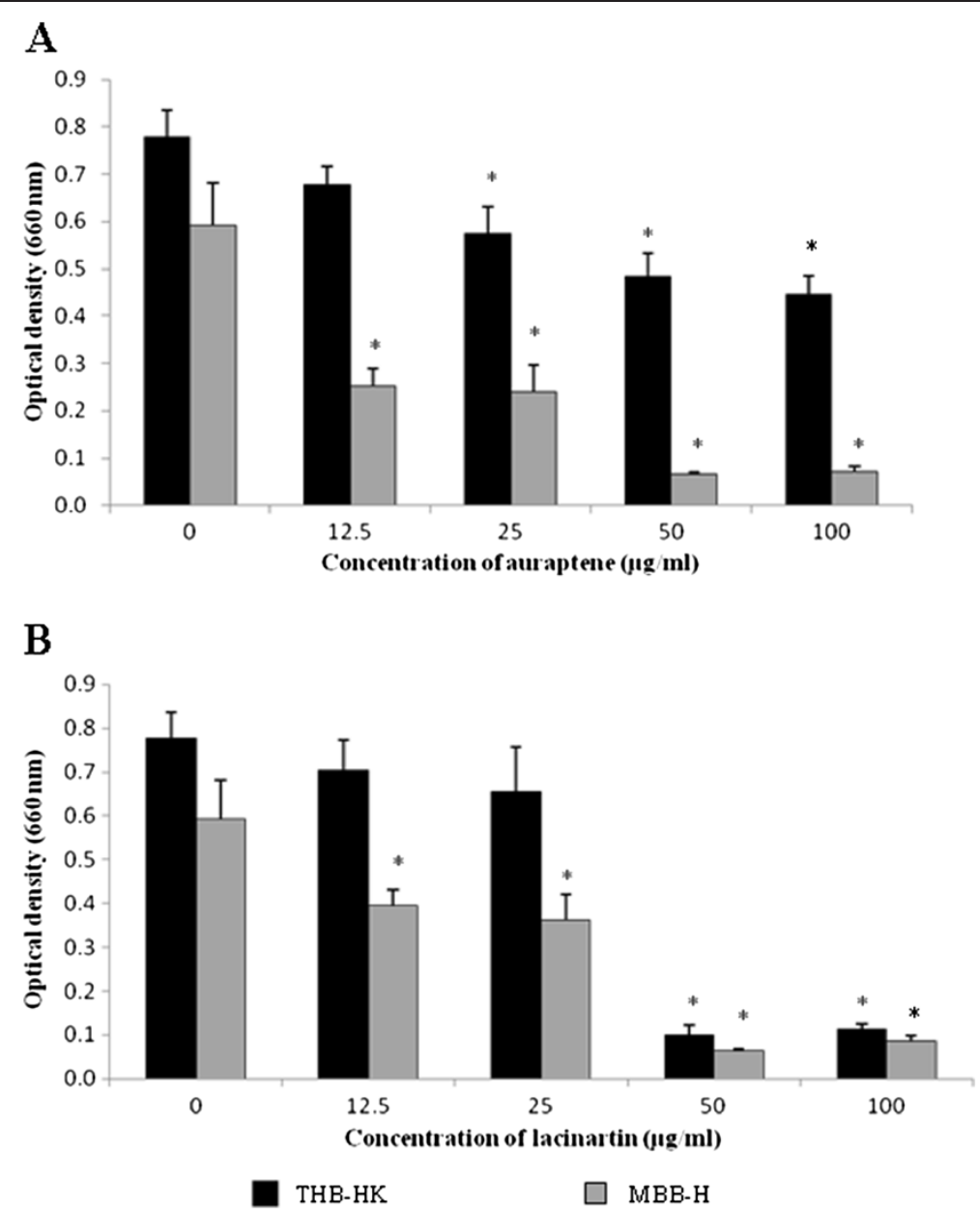

Figure 2 Effect of auraptene (A) and lacinartin (B) on the growth of $P$. gingivalis in a complex medium (THB-HK) and under ironlimiting conditions in MBB-H. Values are expressed as means \pm standard deviations of triplicate assays for a minimum of three independent experiments. Data were analyzed using the Student's t-test (*: $p \leq 0.05$ vs. control without auraptene or lacinartin).

$(\mathrm{v} / \mathrm{v}))$ was added to the wells, and the plate was shaken for $10 \mathrm{~min}$ to release the dye from the biofilms. The absorbance at $550 \mathrm{~nm}\left(\mathrm{~A}_{550}\right)$ was measured to quantify biofilm formation. We also investigated the capacity of auraptene and lacinartin to promote the desorption of a $P$. gingivalis biofilm. Briefly, a 48-h P. gingivalis biofilm was prepared as described above and was treated for $2 \mathrm{~h}$ with auraptene or lacinartin at final concentrations ranging from 0 to $100 \mu \mathrm{g} / \mathrm{ml}$. The biofilms were stained with crystal violet as described above. All the above assays were performed in triplicate.

Effect on $P$. gingivalis adherence to oral epithelial cells $P$. gingivalis cells were first labeled with fluorescein isothyocyanate (FITC). Briefly, a 10-ml aliquot of a 24-h culture (THB-HK) of $P$. gingivalis was centrifuged at $7000 \times \mathrm{g}$ for $10 \mathrm{~min}$, and the pellet was suspended in $12 \mathrm{ml}$ of $0.5 \mathrm{M} \mathrm{NaHCO}_{3}(\mathrm{pH} 8)$ containing $0.03 \mathrm{mg} / \mathrm{ml} \mathrm{FITC}$. The bacterial suspension was incubated in the dark at $37^{\circ} \mathrm{C}$ for
30 min with constant shaking. The bacteria were then washed three times by centrifugation (7000 $\mathrm{x} g$ for $5 \mathrm{~min}$ ) and were suspended in the original volume of PBS. The immortalized human oral epithelial cell line GMSM-K was kindly provided by Dr. Valerie Murrah (University of North Carolina, Chapel Hill, NC, USA). The epithelial cells were cultured in Dulbecco's modified Eagle's medium (DMEM) supplemented with $4 \mathrm{mM}$ L-glutamine (HyClone Laboratories, Logan, UT, USA), 10\% heat-inactivated fetal bovine serum (FBS; Sigma Aldrich Corp.), and $100 \mu \mathrm{g} / \mathrm{ml}$ of penicillin $\mathrm{G} /$ streptomycin at $37^{\circ} \mathrm{C}$ in a $5 \% \mathrm{CO}_{2}$ atmosphere until they reached confluence. The cells were harvested by gentle trypsinization with $0.05 \%$ trypsinethylenediaminetetraacetic acid (Invitrogen, Grand Island, NY, USA) at $37^{\circ} \mathrm{C}$ and were suspended in DMEM (without FBS). Aliquots of cell suspension $\left(100 \mu \mathrm{l}, 1.5 \times 10^{6}\right.$ cells $\left./ \mathrm{ml}\right)$ were placed in the wells of 96-well black plates (Greiner Bio-One, St. Louis, MO, USA). After an overnight incubation to allow the formation a confluent monolayer, spent 

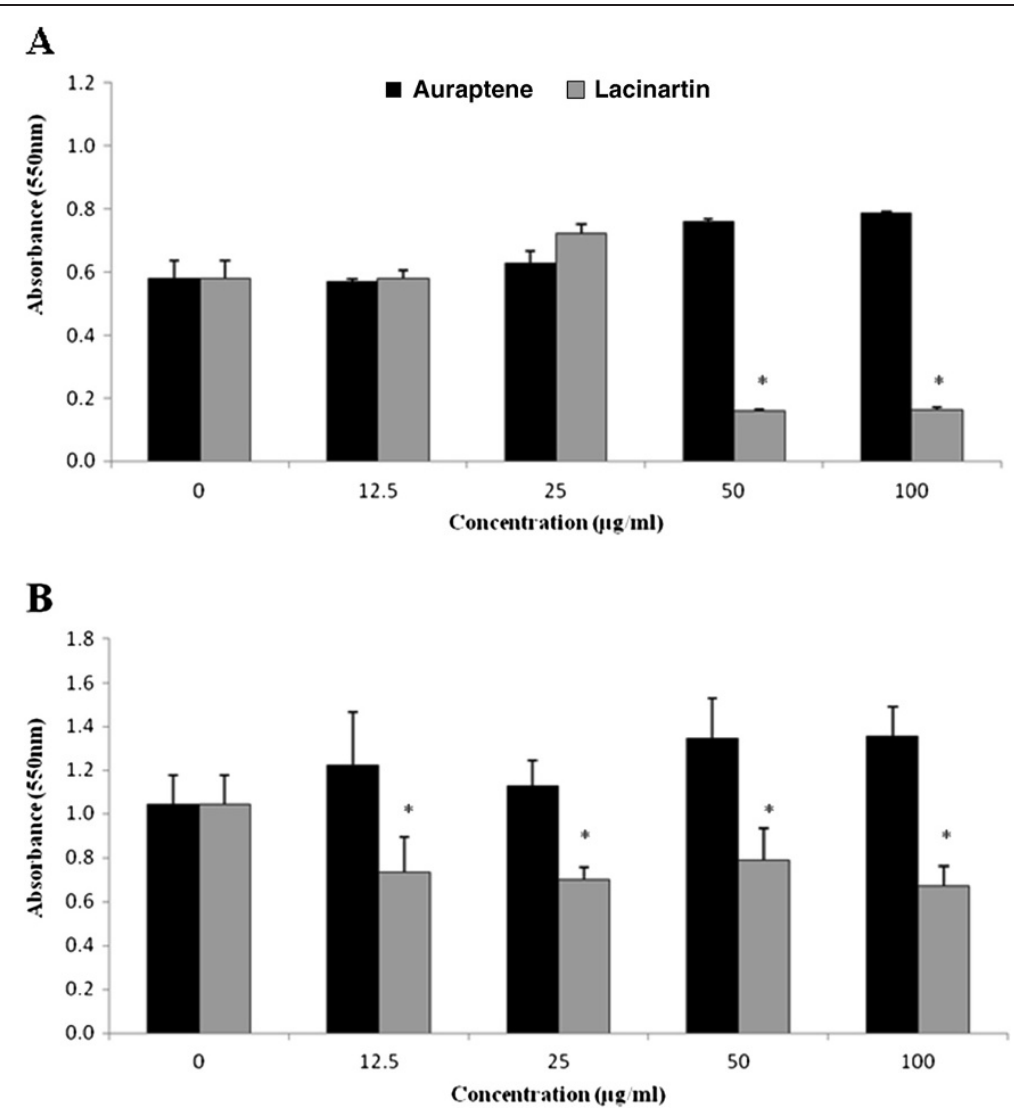

Figure 3 Effect of auraptene and lacinartin on $P$. gingivalis biofilm formation (A) and on desorption of a pre-formed $P$. gingivalis biofilm (B). Values are expressed as means \pm standard deviations of triplicate assays for a minimum of three independent experiments. Data were analyzed with the Student's $t$-test (*: $p \leq 0.05$ vs. control without auraptene or lacinartin).

medium was aspirated, $100 \mu \mathrm{l}$ of formaldehyde (3.7\%) was added to the wells, and the plate was incubated at room temperature for $15 \mathrm{~min}$. The formaldehyde was removed by aspiration and the wells were washed three times with PBS. Filtered 1\% BSA (100 $\mu \mathrm{l})$ was added to each well, and the plate was incubated for $30 \mathrm{~min}$ at $37^{\circ} \mathrm{C}$ in a $5 \% \mathrm{CO}_{2}$ atmosphere. The wells were washed once with PBS, $100 \mu \mathrm{l}$ of auraptene or lacinartin was added to each cell (final concentrations ranging from 0 to $100 \mu \mathrm{g} / \mathrm{ml}$ ), and the plates were incubated for $30 \mathrm{~min}$. The auraptene and lacinartin

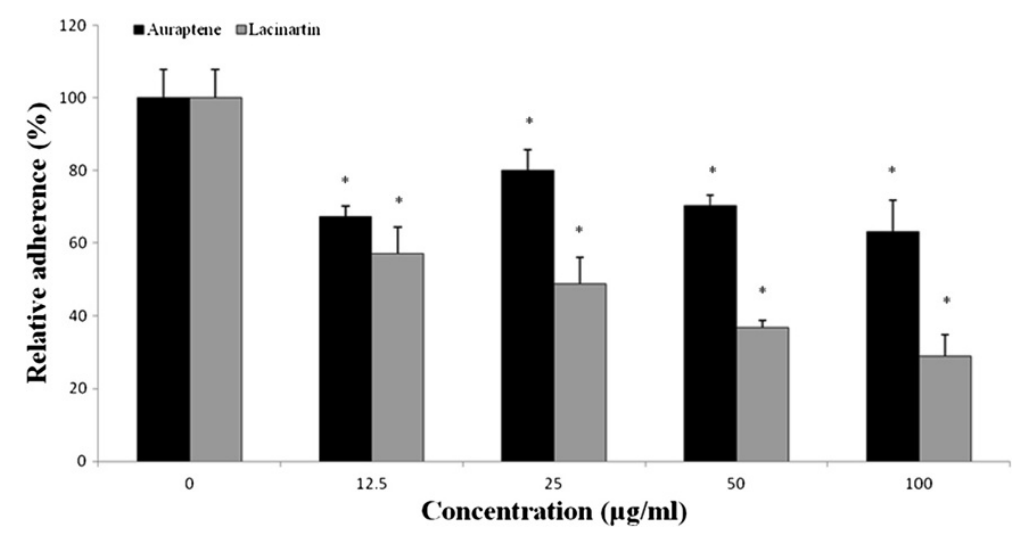

Figure 4 Effect of auraptene and lacinartin on the adherence of $P$. gingivalis to human oral epithelial cells. Values are expressed as means \pm standard deviations of triplicate assays for a minimum of three independent experiments. A value of $100 \%$ was assigned to the control (no auraptene; no lacinartin). Data were analyzed with the Student's $t$-test (*: $p \leq 0.05$ vs. control without auraptene or lacinartin). 

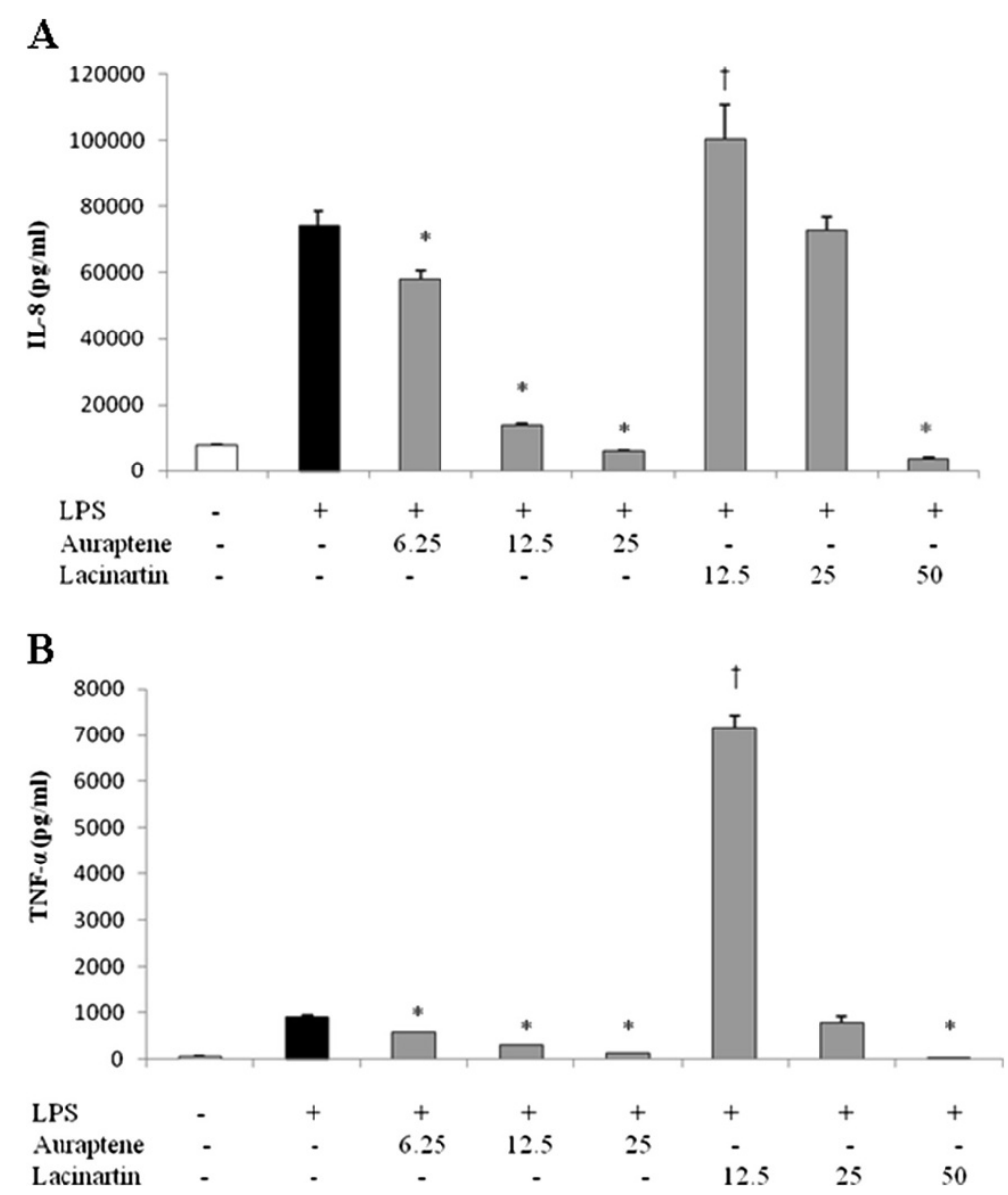

Figure 5 Effect of auraptene and lacinartin on the secretion of IL-8 (A) and TNF-a (B) by human macrophages stimulated with $A$. actinomycetemcomitans LPS $(\mathbf{1} \mathbf{\mu g} / \mathbf{m l})$. Values are expressed as means \pm standard deviations of triplicate assays for a minimum of three independent experiments. Data were analyzed with the Student's $t$-test $\left(^{*}: p \leq 0.05\right.$ vs. untreated control, ${ }^{\dagger}: p \leq 0.05$ vs. control without auraptene or lacinartin).

were not cytotoxic at these concentrations (data not shown). The FITC-labeled $P$. gingivalis cells were then added $(100 \mu \mathrm{l})$ to the wells, and the plates were incubated in the dark for a further $90 \mathrm{~min}$ at $37^{\circ} \mathrm{C}$ under anaerobic conditions. Unbound bacteria were removed by aspiration, and the wells were washed three times with PBS. Relative fluorescence units (RUF; excitation wavelength $495 \mathrm{~nm}$; emission wavelength $525 \mathrm{~nm}$ ) corresponding to the degree of bacterial adherence were determined using a microplate reader. Control wells without auraptene or lacinartin were used to determine $100 \%$ adherence values. Wells containing only cells and auraptene or lacinartin were also prepared to determine the autofluorescence values of the two compounds. The assays were run in triplicate.

\section{Anti-inflammatory properties in a macrophage model} U937 human monocytes (ATCC CRL-1593.2), a monoblastic leukemia cell line, were purchased from the American Type Culture Collection (Manassas, VA, USA). The cells were cultivated at $37^{\circ} \mathrm{C}$ in a $5 \% \mathrm{CO}_{2}$ atmosphere in Roswell Park Memorial Institute 1640 medium (RPMI-1640; HyClone Laboratories) supplemented with $10 \%$ heat-inactivated FBS and $100 \mu \mathrm{g} / \mathrm{ml}$ of penicillin G/streptomycin. The monocytes $\left(2.5 \times 10^{5}\right.$ cells/ml) were then incubated in RPMI-FBS (1\%) containing $10 \mathrm{ng} / \mathrm{ml}$ of phorbol myristic acid (PMA; Sigma Aldrich Corp.) for $48 \mathrm{~h}$ to induce differentiation into adherent macrophage-like cells. Following the PMA treatment, the medium was replaced with fresh medium, and the differentiated cells were incubated for an additional $24 \mathrm{~h}$ prior to use. The macrophages were incubated with auraptene or lacinartin $(6.25$ to $50 \mu \mathrm{g} / \mathrm{ml})$ at $37^{\circ} \mathrm{C}$ in a $5 \% \mathrm{CO}_{2}$ atmosphere for $2 \mathrm{~h}$. They were then stimulated with $1 \mu \mathrm{g} / \mathrm{ml}$ of Aggregatibacter actinomycetemcomitans ATCC 29522 (serotype b) lipopolysaccharide (LPS) isolated using the procedure described by Darveau and Hancock [21]. After a $24-\mathrm{h}$ incubation at $37^{\circ} \mathrm{C}$ in a $5 \%$ $\mathrm{CO}_{2}$ atmosphere, the culture medium supernatants were collected and were stored at $-20^{\circ} \mathrm{C}$ until used. Cells incubated in culture medium with or without auraptene 

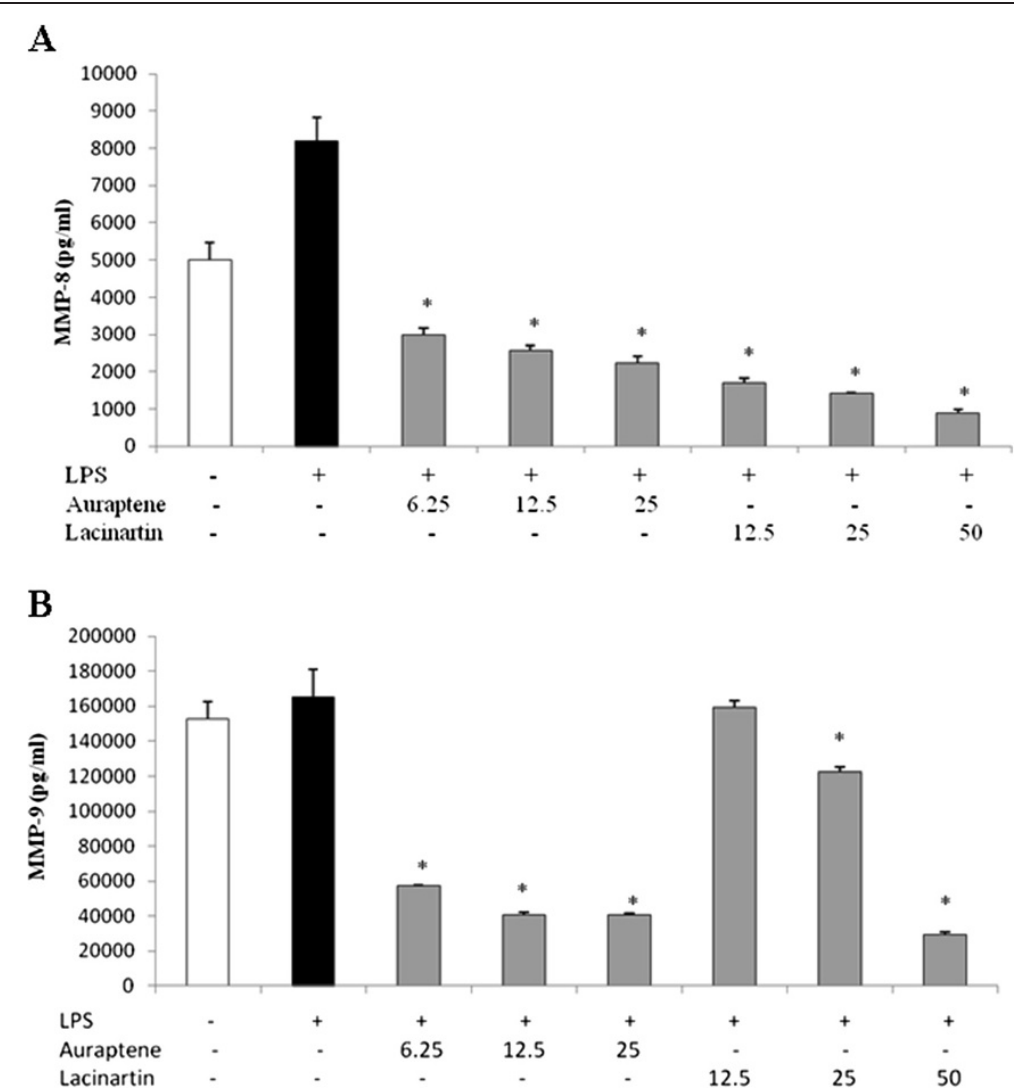

Figure 6 Effect of auraptene and lacinartin on the secretion of MMP-8 (A) and MMP-9 (B) by human macrophages stimulated with $A$. actinomycetemcomitans LPS $(\mathbf{1} \mathbf{\mu g} / \mathbf{m l})$. Values are expressed as means \pm standard deviations of triplicate assays for a minimum of three independent experiments. Data were analyzed with the Student's $t$-test $(*: p \leq 0.05$ vs. untreated control).

or lacinartin but not stimulated with LPS were used as controls. Commercial enzyme-linked immunosorbent assay (ELISA) kits (R\&D Systems, Minneapolis, MN, USA) were used to quantify IL-8, TNF- $\alpha$, MMP-8, and MMP-9 concentrations in the cell-free culture supernatants according to the manufacturer's protocols. The absorbance at $450 \mathrm{~nm}$ was read using a microplate reader with the wavelength correction set at $550 \mathrm{~nm}$.

\section{Inhibition of MMP-9 and $P$. gingivalis collagenase activity}

Human recombinant MMP-9 (active form) purchased from Calbiochem (San Diego, CA, USA) was diluted in reaction buffer $(50 \mathrm{mM}$ Tris- $\mathrm{HCl}, 150 \mathrm{mM} \mathrm{NaCl}, 5 \mathrm{mM}$ $\mathrm{CaCl}_{2}$, and $0.02 \%$ Brij 35) to a concentration of $1 \mu \mathrm{g} / \mathrm{ml}$ and was incubated for $18 \mathrm{~h}$ in the absence or presence of auraptene or lacinartin $(0-100 \mu \mathrm{g} / \mathrm{ml})$ and fluorogenic substrate $(100 \mu \mathrm{g} / \mathrm{ml})$. To determine the effect of auraptene and lacinartin on $P$. gingivalis collagenase activity, a 48-h THB-HK culture was centrifuged at $10000 \mathrm{x} g$ for $10 \mathrm{~min}$. The supernatant was then incubated for $18 \mathrm{~h}$ in the absence or presence of auraptene or lacinartin $(0-100 \mu \mathrm{g} / \mathrm{ml})$ and fluorogenic substrate $(100 \mu \mathrm{g} / \mathrm{ml})$. Gelatin $\mathrm{DQ}^{\mathrm{TM}}$ and collagen $\mathrm{DQ}^{\mathrm{TM}}$ (Molecular Probes, Eugene, OR, USA) were used to quantify MMP-9 and P. gingivalis collagenase activities, respectively. The assay mixtures were incubated for $18 \mathrm{~h}$ at $37^{\circ} \mathrm{C}$ for MMP-9 and at room temperature for $P$. gingivalis collagenase. The fluorescence was measured after $4 \mathrm{~h}$ using a microplate reader with the excitation and emission wavelengths set at $495 \mathrm{~nm}$ and $525 \mathrm{~nm}$, respectively. Fluorescent substrates alone or with auraptene and lacinartin were used as controls. Specific inhibitors of MMP-9 (0.025 $\mu \mathrm{M}$ GM6001) and P. gingivalis collagenase ( $1 \mu \mathrm{M}$ leupeptin) were tested. The assays were run in triplicate.

\section{Statistical analysis}

Results are expressed as the means \pm standard deviations of three independent experiments. The data were analyzed using the Student's t-test. A $p$ value $\leq 0.05$ was considered statistically significant.

\section{Results}

Lacinartin (50 and $100 \mu \mathrm{g} / \mathrm{ml}$ ) almost completely inhibited the growth of $P$. gingivalis in THB-HK (Figure. 2B), while the highest concentration of auraptene tested $(100 \mu \mathrm{g} / \mathrm{ml})$ only reduced growth by $42 \%$ (Figure. 2A). 
Table 1 Effect of auraptene and lacinartin on the activity of MMP-9 and $P$. gingivalis collagenase

\begin{tabular}{|c|c|c|}
\hline Compound & $\begin{array}{l}\text { MMP-9 } \\
\text { (\% activity) }\end{array}$ & $\begin{array}{l}\text { Collagenase } \\
\text { (\% activity) }\end{array}$ \\
\hline None & $100 \pm 1$ & $100 \pm 3$ \\
\hline Commercial inhibitor $^{1}$ & $56 \pm 1$ & $6 \pm 5$ \\
\hline Auraptene 100 mg/ml & $27 \pm 1$ & $110 \pm 4$ \\
\hline 50 & $27 \pm 1$ & $113 \pm 5$ \\
\hline 25 & $27 \pm 3$ & $113 \pm 1$ \\
\hline 12.5 & $26 \pm 1$ & $107 \pm 10$ \\
\hline Lacinartin $100 \mu \mathrm{g} / \mathrm{ml}$ & $19 \pm 6$ & $36 \pm 3$ \\
\hline 50 & $25 \pm 1$ & $49 \pm 1$ \\
\hline 25 & $31 \pm 2$ & $69 \pm 1$ \\
\hline 12.5 & $26 \pm 3$ & $80 \pm 1$ \\
\hline
\end{tabular}

'Inhibitor of MMP-9: GM6001 (0.025 $\mu$ M); inhibitor of $P$. gingivalis collagenase: leupeptin $(1 \mu \mathrm{M})$

Bacterial growth was slightly lower in $\mathrm{MBB}-\mathrm{H}\left(\mathrm{OD}_{660}=\right.$ 0.59), which represents an iron poor condition for $P$. gingivalis, than in THB-HK $\left(\mathrm{OD}_{660}=0.78\right)$ (Figure. 2). The lowest concentration of auraptene tested $(12.5 \mu \mathrm{g} /$ $\mathrm{ml}$ ) inhibited growth by $58 \%$ in $\mathrm{MBB}-\mathrm{H}$, while such a concentration had no significant inhibitory effect in THB-HK (Figure. 2A). Almost complete inhibition was observed at higher concentrations (50 and $100 \mu \mathrm{g} / \mathrm{ml}$ ). As for auraptene, lacinartin seemed to be more effective for inhibiting growth of $P$. gingivalis in iron-limiting conditions.

Auraptene had no obvious inhibitory effect on $P$. gingivalis biofilm formation or desorption (Figure. 3 ). On the contrary, high concentrations (50 and $100 \mu \mathrm{g} / \mathrm{ml}$ ) of auraptene appear to increase biofilm formation (Figure. 3A). Lacinartin at 50 and $100 \mu \mathrm{g} / \mathrm{ml}$ inhibited biofilm formation by $P$. gingivalis by approximately $75 \%$ (Figure. 3A). In addition, lacinartin (12.5-100 $\mu \mathrm{g} / \mathrm{ml})$ caused approximately one-third of the biofilm to desorb (Figure. 3B).

Auraptene and lacinartin both dose-dependently inhibited bacterial adhesion to oral epithelial cells (Figure. 4). At the lowest concentration tested $(12.5 \mu \mathrm{g} / \mathrm{ml})$, auraptene and lacinartin reduced the adherence of $P$. gingivalis to epithelial cells by $33 \%$ and $43 \%$, respectively, while $100 \mu \mathrm{g} / \mathrm{ml}$ of auraptene and lacinartin reduced adherence by $37 \%$ and $71 \%$, respectively (Figure. 4 ).

The highest non-cytotoxic concentrations of auraptene and lacinartin that can be used to evaluate their effect on the inflammatory response of a human macrophage model stimulated with LPS were 25 and $50 \mu \mathrm{g} / \mathrm{ml}$, respectively (data not shown). Following a 2-h pretreatment of the model with auraptene $(6.25,12.5$, and $25 \mu \mathrm{g} / \mathrm{ml})$ or lacinartin $(12.5,25$, and $50 \mu \mathrm{g} / \mathrm{ml})$, macrophages were stimulated with LPS to induce an inflammatory response (cytokine and MMP secretion). Auraptene and lacinartin both had a significant inhibitory effect on IL- 8 and TNF- $\alpha$ secretion. At the lowest concentration tested $(6.25 \mu \mathrm{g} / \mathrm{ml})$, auraptene reduced IL- 8 and TNF- $\alpha$ secretion by $22 \%$ and $37 \%$, respectively, compared to untreated cells, while at the highest concentration tested $(25 \mu \mathrm{g} / \mathrm{ml})$, it inhibited IL-8 and TNF$\alpha$ secretion by $92 \%$ and $85 \%$, respectively (Figure. 5 ). As shown in Fig. 5, the highest concentration of lacinartin tested $(50 \mu \mathrm{g} / \mathrm{ml})$ reduced IL- 8 and TNF- $\alpha$ secretion by $95 \%$ and $99 \%$, respectively, while 12.5 and $25 \mu \mathrm{g} / \mathrm{ml}$ of lacinartin increased the secretion of both cytokines, likely due to a synergistic effect of LPS and lacinartin, since lacinartin alone had no effect (data not shown). Auraptene and lacinartin both reduced MMP-8 and MMP-9 secretion, sometimes below basal levels (Figure. 6). Auraptene reduced MMP-8 secretion by $63 \%(6.25 \mu \mathrm{g} / \mathrm{ml}), 69 \%(12.5 \mu \mathrm{g} / \mathrm{ml})$, and $73 \%(25 \mu \mathrm{g} / \mathrm{ml})$, while lacinartin reduced MMP-8 secretion by $79 \%(12.5 \mu \mathrm{g} / \mathrm{ml}), 83 \%(25 \mu \mathrm{g} / \mathrm{ml})$, and $89 \%$ $(50 \mu \mathrm{g} / \mathrm{ml})$ (Figure. 6A). At their highest concentrations tested, auraptene $(25 \mu \mathrm{g} / \mathrm{ml})$ reduced MMP- 9 secretion by $76 \%(25 \mu \mathrm{g} / \mathrm{ml})$ (Figure. 6B), while lacinartin $(50 \mu \mathrm{g} / \mathrm{ml})$ reduced MMP-9 secretion by $82 \%$ (Figure. 6B).

After demonstrating that auraptene and lacinartin can decrease MMP secretion in a macrophage model, we evaluated their effect on proteinase activity. Both auraptene and lacinartin $(12.5 \mu \mathrm{g} / \mathrm{ml})$ reduced MMP-9 activity by $74 \%$ (Table 1 ). Auraptene had no inhibitory effect on $P$. gingivalis collagenase activity while $12.5 \mu \mathrm{g} / \mathrm{ml}$ and $100 \mu \mathrm{g} / \mathrm{ml}$ of lacinartin reduced collagenase activity by $20 \%$ and $64 \%$, respectively (Table 1 ).

\section{Discussion}

Periodontal diseases are polymicrobial infections and are the most common chronic inflammatory disorders in adults [22]. Periodontitis is induced by a specific group of Gram-negative anaerobic bacteria and is the major cause of tooth loss in adults [23]. Over the past two decades, natural compounds with antibacterial and antiinflammatory properties have received considerable attention as new therapeutic agents for the treatment of periodontal infections. In this study, we investigated the potential of auraptene and lacinartin for preventing and treating periodontal diseases.

We first showed that lacinartin and to a lesser extent auraptene reduced $P$. gingivalis growth. This is the first report indicating that lacinartin possesses anti-bacterial properties. Previous studies have shown that auraptene has antibacterial properties against Helicobacter pylori $[24,25]$. The exact mechanism by which lacinartin and auraptene inhibit bacterial growth is unknown. However, other natural coumarins (novobiocin and clorobiocin) inhibit deoxyribonuclease gyrase activity, which results in bacteria death $[14,26]$. In addition, we showed that auraptene and lacinartin inhibit growth more effectively under iron-limiting conditions, requiring much lower 
concentrations to significantly reduce the growth of $P$. gingivalis. Our results are in agreement with those of Mladnka et al. [27], who showed that coumarins possess iron-chelating properties. Additional studies are required to investigate interactions between iron and auraptene and lacinartin.

We also showed that lacinartin, but not auraptene, inhibits biofilm formation by $P$. gingivalis. Lacinartin also caused the desorption of a pre-formed $P$. gingivalis biofilm. To the best of our knowledge, this is the first report regarding the inhibitory effects of lacinartin on bacterial biofilms. Auraptene and lacinartin prevented the adherence of $P$. gingivalis to oral epithelial cells to a significant degree. Epithelial cells act as a physical barrier, and bacterial adherence to these host cells may be a critical step for the initiation of periodontal diseases [28]. Given its ability to reduce growth of $P$. gingivalis and its adherence to epithelial cells, lacinartin may be a promising therapeutic candidate through its action on different targets.

Polyphenols reduce inflammatory mediator secretion and, as such, inflammation-mediated damage [29]. We showed that auraptene markedly reduces IL- 8 and TNF$\alpha$ secretion by LPS-stimulated macrophages. Our results are in agreement with those of Genovese et al., who reported that auraptene inhibits the release of TNF- $\alpha$ by RAW 264.7 macrophages [30]. To our knowledge, no one has investigated the anti-inflammatory properties of lacinartin. We showed that $12.5 \mu \mathrm{g} / \mathrm{ml}$ of lacinartin induced IL- 8 and TNF- $\alpha$ secretion, likely due to a synergistic interaction between LPS and lacinartin. On the other hand, $50 \mu \mathrm{g} / \mathrm{ml}$ of lacinartin significantly inhibited IL- 8 and TNF- $\alpha$ secretion. We also showed that auraptene and lacinartin reduced MMP-8 and MMP-9 secretion. These results are in agreement with those of a study by Epifano et al., who reported that auraptene inhibits MMP-7 secretion by HT-29 epithelial cells [18]. Since MMP release and cytokine secretion are associated with tooth-supporting tissue destruction, our results suggested that both compounds may contribute to reducing host cell damage, including bone resorption [5,31]. The mechanisms by which auraptene and lacinartin reduce inflammatory mediator secretion are unknown, but previous studies have shown that coumarins can block the activation of nuclear factor $-\mathrm{k} B$ and inhibit kinase pathways (Akt/PKB) [26]. Considering that gingival fibroblasts may also play a significant role in periodontal tissue destruction through cytokine-inducible MMP secretion, future studies should investigate the effects of auraptene and lacinartin on this cell type.

We further showed that auraptene and lacinartin reduce MMP-9 activity while only lacinartin inhibits $P$. gingivalis collagenase activity. Auraptene has previously been shown to inhibit MMP-7 activity [32]. These observations suggest that these coumarins may contribute to reducing tissue destruction.

\section{Conclusions}

In conclusion, our study provided new information on auraptene and lacinartin indicating that they possess an array of interesting antimicrobial, anti-adhesion, antiinflammatory and anti-protease properties that may be useful for the prevention and treatment of periodontal diseases. Since auraptene and lacinartin act on both etiologic factors of periodontal diseases (periodontopathogens and the host inflammatory response), they may be an alternative to traditional antimicrobials. Further studies are required to investigate the mechanisms of these coumarins, especially the mechanisms involved in their anti-inflammatory activity.

\section{Competing interests}

The authors declare that they have no competing interests.

\section{Authors' contributions}

All authors contributed equally in data acquisition and in writing of the manuscript. All the authors read and approved the final version of the manuscript.

\section{Acknowledgements}

This study was financially supported by an International Association for Dental Research/GlaxoSmithKline Innovation in Oral Care Award.

\section{Author details}

${ }^{1}$ Groupe de Recherche en Écologie Buccale, Faculté de Médecine Dentaire, Université Laval, 2420 Rue de la Terrasse, Quebec City, QC, Canada G1V OA6. 2Dipartimento di Science del Farmaco, Università G. D'Annunzio, Via Dei Vestini 31, 66013 Chieti Scalo Chieti, Italy.

Received: 2 March 2012 Accepted: 28 June 2012

Published: 28 June 2012

\section{References}

1. Highfield J: Diagnosis and classification of periodontal disease. Aust Dent J 2009, 54(Suppl 1):S11-26.

2. Burt B: Position paper: epidemiology of periodontal diseases. J Periodontol 2005, 76(8):1406-1419.

3. Feng $Z$, Weinberg $A$ : Role of bacteria in health and disease of periodontal tissues. Periodontol 2000 2006, 40:50-76.

4. Aas JA, Paster BJ, Stokes LN, Olsen I, Dewhirst FE: Defining the normal bacterial flora of the oral cavity. J Clin Microbiol 2005, 43(11):5721-5732.

5. Holt SC, Ebersole JL: Porphyromonas gingivalis, Treponema denticola, and Tannerella forsythia: the "red complex", a prototype polybacterial pathogenic consortium in periodontitis. Periodontol 2000 2005, 38:72-122.

6. Garlet GP: Destructive and protective roles of cytokines in periodontitis: a re-appraisal from host defense and tissue destruction viewpoints. J Dent Res 2010, 89(12):1349-1363.

7. Kornman KS, Page RC, Tonetti MS: The host response to the microbial challenge in periodontitis: assembling the players. Periodontol 20001997, 14:33-53.

8. Pandey KB, Rizvi SI: Plant polyphenols as dietary antioxidants in human health and disease. Oxid Med Cell Longev 2009, 2(5):270-278.

9. Scalbert A, Johnson IT, Saltmarsh M: Polyphenols: antioxidants and beyond. Am J Clin Nutr 2005, 81(1 Suppl):215S-217S.

10. El Gharras H: Polyphenols: food sources, properties and applications - a review. Int J Food Sci Technol 2009, 44(12):2512-2518.

11. Bravo L: Polyphenols: chemistry, dietary sources, metabolism, and nutritional significance. Nutr Rev 1998, 56(11):317-333. 
12. Cos P, De Bruyne T, Hermans N, Apers S, Berghe DV, Vlietinck AJ: Proanthocyanidins in health care: current and new trends. Curr Med Chem 2004, 11(10):1345-1359.

13. Genovese S, Epifano F: Auraptene: a natural biologically active compound with multiple targets. Curr Drug Targets 2011, 12(3):381-386.

14. Borges F, Roleira F, Milhazes N, Santana L, Uriarte E: Simple coumarins and analogues in medicinal chemistry: occurrence, synthesis and biological activity. Curr Med Chem 2005, 12(8):887-916.

15. Komatsu S, Tanaka S, Ozawa S, Kubo R, Ono Y, Matsuda Z: Biochemical studies on grape fruits, Citrus aurantium. Nippon Kagaku Kaishi 1930, 51:478-498.

16. Nagao K, Yamano N, Shirouchi B, Inoue N, Murakami S, Sasaki T, Yanagita T: Effects of citrus auraptene (7-geranyloxycoumarin) on hepatic lipid metabolism in vitro and in vivo. J Agric Food Chem 2010, 58(16):9028-9032.

17. Ogawa K, Kawasaki A, Yoshida T, Nesumi H, Nakano M, Ikoma Y, Yano M: Evaluation of auraptene content in citrus fruits and their products. J Agric Food Chem 2000, 48(5):1763-1769.

18. Epifano F, Genovese S, Curini M: Auraptene: Phytochemical and pharmacological properties. In Phytochemistry Research Progress. Edited by Matsumoto T. Hauppaughe,NY (USA): Nova Science Publishers Inc: 2008:145-162.

19. Tanaka T, Kawabata K, Kakumoto M, Matsunaga K, Mori H, Murakami A, Kuki W, Takahashi Y, Yonei H, Satoh K, et al: Chemoprevention of 4nitroquinoline 1-oxide-induced oral carcinogenesis by citrus auraptene in rats. Carcinogenesis 1998, 19(3):425-431.

20. Genovese S, Epifano F, Curini M, Dudra-Jastrzebska M, Luszczki J J: Prenyloxyphenylpropanoids as a novel class of anticonvulsive agents. Bioorg Med Chem Lett 2009, 19(18):5419-5422.

21. Darveau RP, Hancock RE: Procedure for isolation of bacterial lipopolysaccharides from both smooth and rough Pseudomonas aeruginosa and Salmonella typhimurium strains. J Bacteriol 1983, 155(2):831-838.

22. Darveau RP: Periodontitis: a polymicrobial disruption of host homeostasis. Nat Rev Microbiol 2010, 8(7):481-490

23. Pihlstrom BL, Michalowicz BS, Johnson NW: Periodontal diseases. Lancet 2005, 366(9499):1809-1820

24. Epifano F, Menghini L, Pagiotti R, Angelini P, Genovese S, Curini M: In vitro inhibitory activity of boropinic acid against Helicobacter pylori. Bioorg Med Chem Lett 2006, 16(21):5523-5525.

25. Takeda K, Utsunomiya H, Kakiuchi S, Okuno Y, Oda K, Inada K, Tsutsumi Y, Tanaka T, Kakudo K: Citrus auraptene reduces Helicobacter pylori colonization of glandular stomach lesions in Mongolian gerbils. J Oleo SCi 2007, 56(5):253-260

26. Wu L, Wang $X, X u$ W, Farzaneh F, Xu R: The structure and pharmacological functions of coumarins and their derivatives. Curr Med Chem 2009, 16(32):4236-4260.

27. Mladenka P, Macakova K, Zatloukalova L, Rehakova Z, Singh BK, Prasad AK, Parmar VS, Jahodar L, Hrdina R, Saso L: In vitro interactions of coumarins with iron. Biochimie 2010, 92(9):1108-1114.

28. Andrian E, Grenier D, Rouabhia M: Porphyromonas gingivalis-epithelial cell interactions in periodontitis. J Dent Res 2006, 85(5):392-403.

29. Nijveldt RJ, van Nood E, van Hoorn DE, Boelens PG, van Norren K, van Leeuwen PA: Flavonoids: a review of probable mechanisms of action and potential applications. Am J Clin Nutr 2001, 74(4):418-425.

30. Genovese S, Curini M, Epifano F: Prenyloxyphenylpropanoids as a nove class of anti-inflammatory agents. Anti-Inflammatory \& Anti-Allergy Agents in Medicinal Chemistry 2010, 9(2):158-165.

31. Okada H, Murakami S: Cytokine expression in periodontal health and disease. Crit Rev Oral Biol Med 1998, 9(3):248-266.

32. Kawabata K, Murakami A, Ohigashi H: Auraptene decreases the activity of matrix metalloproteinases in dextran sulfate sodium-induced ulcerative colitis in ICR mice. Biosci Biotechnol Biochem 2006, 70(12):3062-3065.

doi:10.1186/1472-6882-12-80

Cite this article as: Marquis et al:: The plant coumarins auraptene and lacinartin as potential multifunctional therapeutic agents for treating periodontal disease. BMC Complementary and Alternative Medicine 2012 $12 \cdot 80$

\section{Submit your next manuscript to BioMed Central and take full advantage of:}

- Convenient online submission

- Thorough peer review

- No space constraints or color figure charges

- Immediate publication on acceptance

- Inclusion in PubMed, CAS, Scopus and Google Scholar

- Research which is freely available for redistribution 